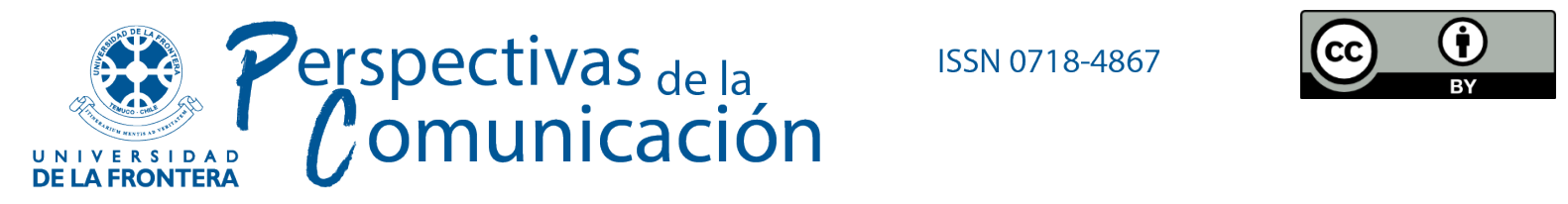

Artículo

\title{
LA ESTRATEGIA COMUNICATIVA EN LOS DISCURSOS DE TOMA DE POSESIÓN DE CRISTINA FERNÁNDEZ DE KIRCHNER
}

https://doi.org/OO.OOO/COO-202O-O1

Dra. Idoia Camacho Markina

Universidad del País Vasco/Euskal Herriko Unibertsitatea, Leioa, España

idoia.camacho@ehu.eus

ORCID iD: orcid.org/0000-0003-2296-9472

Dra. María Teresa Santos Diez

Universidad del País Vasco/Euskal Herriko Unibertsitatea, Leioa, España

mariateresa.santos@ehu.eus

ORCID iD: orcid.org/o000-0002-2494-3279

Recibido el 19 de junio de 2018

Aceptado el 10 de septiembre de 2020

\section{Resumen}

Este artículo tiene como objetivo indagar en la estrategia comunicativa de Cristina Fernández de Kirchner cuando era presidenta de la República Argentina (2007-2015), a través del análisis de los dos discursos que pronunció en las tomas de posesión. Se identificaron las características populistas que se manifiestan en dichos discursos, de acuerdo con los conceptos propuestos por Patrick Charaudeau (descripción catastrófica, denuncia de los culpables, exaltación de valores y aparición del salvador/a de la sociedad), para comprobar cuál es la imagen que la Mandataria quiere transmitir en ellos, sobre sí misma y sobre el público receptor. Para ello, se empleó desde la teoría del framing, según la cual los líderes políticos realizan una construcción selectiva de la realidad, enfatizando y omitiendo aspectos cruciales en sus intervenciones públicas. Las conclusiones muestran que la presidenta se presenta como salvadora de la sociedad, que se menciona a sí misma en numerosas ocasiones y siempre de forma positiva, que menciona al público receptor con 
menor frecuencia que a ella misma y que lo hace mediante cualidades principalmente pasivas.

Palabras clave: Cristina Fernández de Kirchner, discurso, análisis de contenido, framing, comunicación política. 


\title{
CRISTINA FERNÁNDEZ DE KIRCHNER'S COMMUNICATION STRATEGY IN THE SPEECHES AT HER SWEARING-IN CEREMONIES
}

\begin{abstract}
This article aims to investigate Cristina Fernández de Kirchner's communication strategy when she was President of the Republic of Argentina (2007-2015), through the analysis of the two speeches given on both swearing-in ceremonies. We identified the populist characteristics that are present in these speeches, according to the concepts proposed by Patrick Charaudeau (catastrophic description, denouncing of culpable parts, exaltation of values and the emergence of the rescuer of society), so as to evaluate the image that the President wants to transmit of herself and of the receiving public. To do this, we used the method of quantitative and qualitative content analysis and applied the theory of framing, according to which political leaders construct reality in a selective way, emphasizing and omitting crucial aspects in their public interventions. The findings show that President presents herself as a rescuer of society, who mentions herself frequently and always in a positive way, who mentions the receiving audience less frequently than herself and that she attributes mainly passive qualities to them.
\end{abstract}

Keywords: Cristina Fernández de Kirchner, speech, content analysis, framing, political communication. 


\section{Introducción}

Cristina Fernández de Kirchner fue la primera mujer electa presidenta en Argentina y la segunda en ejercer el cargo, que ocupó desde el 10 de diciembre de 2007 hasta el 9 de diciembre de 2015, durante dos mandatos consecutivos (2007-2011 y 2011-2015). Desarrolló el movimiento político conocido como Kirchnerismo, de orientación peronista, iniciado en el año 2003 con la candidatura presidencial de su esposo Néstor Kirchner -que fue presidente desde ese año hasta 2007.

Antes de acceder a la jefatura de la Nación, Cristina Fernández tenía una larga trayectoria en la política argentina, ya que había ocupado varios cargos como diputada y senadora. Esa trayectoria constituía una circunstancia favorable para su aspiración a la presidencia; sin embargo, "el hecho de que el presidente saliente fuese su marido contara con altos índices de popularidad y estuviese facultado para aspirar a la reelección planteaba varios desafíos a la construcción discursiva de su imagen pública" (Vitale y Maizels, 2011: 338). En el plano de la estrategia política y comunicativa, su situación impedía a la Mandataria oponerse a la gestión del momento y la obligaba a presentarse como continuadora de esta, al mismo tiempo que le exigía cierta diferenciación para cobrar una identidad propia.

El estudio de la identidad kirchnerista y de los discursos pronunciados por sus presidentes ha ganado espacio en las investigaciones de los últimos años y ha sido abordado desde diversos enfoques y disciplinas, aunque la mayor parte de ellos se refieren al ámbito de la Teoría Política y del Análisis del Discurso. Montero (2009) examinó los discursos presidenciales de Néstor Kirchner durante su mandato y determinó que estos desarrollan la estrategia del peronismo y construyen una identidad política kirchnerista caracterizada por la puesta en escena de amistades y enemistades entre diversos personajes. Bermúdez (2014) también analizó los discursos del presidente argentino, centrándose en su dimensión emocional, que se caracteriza por la construcción discursiva del coraje o valentía para desencadenar admiración entre los ciudadanos. Vitale y Maizels (2011) estudiaron tres discursos pronunciados por Cristina Fernández en su campaña presidencial de 2007 y demostraron que en ellos se construyeron dos imágenes preponderantes: la del ethos pedagógico-experto y la del ethos de la feminidad. Por otro lado, Gindin (2016) analizó el modo en que se representan ciertos acontecimientos del pasado en el discurso del primer mandato de Cristina Fernández, y concluyó que la presidenta juega el papel de la enunciadora como agente activo de una reescritura de la historia, que pone al kirchnerismo en el centro de la escena y cohesiona su propia identidad. 
El kirchnerismo en Argentina ha sido calificado por varios autores (Laclau, 2006; Novaro, 2006; Biglieri y Perelló, 2007; Retamozo, 2014) como uno de los casos de retorno del populismo en América Latina. La estrategia comunicativa de Néstor Kirchner y Cristina Fernández se inscribe en la forma de actuar de los mandatarios populistas, que consiste en evitar la participación de medios enfrentados al gobierno y en negar la posibilidad de que los periodistas intervengan en el flujo comunicativo entre el líder político y la ciudadanía, para minimizar la mediación periodística que pueda colocar preguntas incómodas o introducir temas fuera del interés oficial (Amado, 2015: 80). A través de este tipo de estrategia, los gobernantes se concentran en hacer que el contenido de sus mensajes llegue íntegramente a la ciudadanía en un sistema de comunicación directa, y para ello obstaculizan y restringen fuertemente la mediación periodística. De esta manera, pretenden tutelar los significados que se transmiten de sus actividades y la imagen que se difunde de ellos a través de los medios de comunicación, con el objetivo de conseguir una construcción mediática de la realidad política favorable a sus intereses (Casero, 2009). Se trata de un sistema de flujo de comunicación topdown del actor político a los medios y a los ciudadanos (Mazzoleni, 2010: 33).

Los Kirchner son el prototipo del control del mensaje para marcar el ritmo y la agenda pública, y que no sean ni sus adversarios ni la prensa quienes decidan de qué se habla y cómo se habla (Arroyo, 2012: 376). Al mismo tiempo que intervenían en el terreno mediático para minimizar la intermediación periodística, los dos presidentes "dieron una centralidad retórica a la acción de la prensa, a partir de una interpelación directa a su discurso como verdaderos enemigos del pueblo y mediadores que obstaculizan la relación directa entre la gestión y los argentinos" (Diego, 2014: 14), planteando un conflicto entre ambos actores en términos de dos polos contrapuestos que disputan poder político en el espacio público.

El mandato de Néstor Kirchner se caracterizó por una mezcla contradictoria de tensión en su relación con los medios de comunicación y de la búsqueda permanente de la complicidad de ciertos medios. Restringió los contactos con los periodistas, concedió muy pocas entrevistas y nunca respondió preguntas en conferencia de prensa, mientras concentraba la información que ofrecía en el diario de mayor circulación del país, al que beneficiaba con exclusivas y conversaciones off the record, lo que sentó las bases para consolidar un sistema de propaganda y medios oficiales. Pero, lejos de ignorarlos, vivió obsesionado por aquello que los medios de comunicación informaban sobre su gestión (O’Donnell, 2008: 40) y buscó 
deslegitimarlos como mediadores privilegiados entre el poder político y la opinión pública (Vincent, 2011: 79).

La tendencia de intervención mediática y propaganda oficial del periodo 2003-2007 se consolidó con la llegada a la presidencia de Cristina Fernández de Kirchner, quien ya en su campaña electoral evitó responder a preguntas de los periodistas. Una vez en el cargo, restringió aún más el contacto con los periodistas y se limitó a ofrecer entrevistas a medios internacionales y a unos pocos locales. Decidió llevar a cabo una estrategia de comunicación directa con la ciudadanía, que consistía en comunicar exclusivamente a través de sus discursos y mensajes institucionales. Al mismo tiempo, consolidó el sistema de propaganda y control de lo publicado, evitando que la prensa tuviera acceso a las actividades oficiales, con excepción de los medios estatales y algunos otros de afinidad manifiesta al partido gobernante (Amado, 2015: 64). Así, los periodistas se veían obligados a cubrir los eventos a partir del material producido por agencias que dependían de la Secretaría de Comunicación Pública. Esta práctica comunicativa marcada por la conflictividad puso en disputa los lugares instituidos de enunciación pública y terminó transformando la dinámica de relaciones entre los medios, los actores del sistema político y la ciudadanía (Fernández, 2014: 41). De hecho, las narrativas del gobierno kirchnerista acerca de la naturaleza políticamente interesada y sesgada de las grandes empresas de medios provocaron que sus simpatizantes confiaran menos en los medios que el resto de la población (Lodola y Kitzberger, 2017: 655).

El propósito de este trabajo es contribuir a la investigación sobre la comunicación de los líderes políticos, concretamente sobre los discursos de Cristina Fernández de Kirchner, desde el ámbito de la comunicación política, mediante un análisis de contenido que incorpora el punto de vista del framing.

\section{El discurso populista}

El populismo como discurso político ha sido analizado por diversos autores a partir de los trabajos pioneros de Laclau (1978, 2005, 2006), quien entiende que el discurso populista es un tipo de discurso político de naturaleza antagónica, pronunciado por un líder que se dirige a los individuos como miembros de un "pueblo", en oposición a las élites dominantes, contra las que los moviliza. "El populismo incluye demandas socialistas, una defensa vigorosa de la pequeña propiedad, fuertes componentes nacionalistas y la negación de la importancia de la clase, acompañado de la afirmación de los derechos de la gente común como enfrentados a 
los privilegiados, generalmente considerados contrarios al pueblo y a la nación" (Laclau, 2005: 16).

Sin embargo, la imagen del pueblo que el populismo recrea en sus discursos es imprecisa y varía dependiendo del autor que la defina. Para Dussel (2007: 11), el populismo considera a toda la comunidad como el pueblo, incluyendo a las clases, sectores de clase y grupos, que constituyen el bloque histórico en el poder que sería necesario derrocar. El "pueblo" se confunde así con la "nación”. La elección de una u otra concepción por parte del líder político evidencia una clara intención comunicativa, que se manifiesta en sus discursos optando por apelar al conjunto de la ciudadanía o solo a los sectores más desfavorecidos.

Siguiendo a Charaudeau (2009b: 257), el término "populista" toma sentidos particulares según el sujeto hablante que lo utiliza. Así, aunque a menudo se emplea como equivalente de demagógico, cuando los sujetos que hablan son políticos lo suelen utilizar para estigmatizar al partido adversario, para ellos el populista siempre es el otro. "Muchas veces para la derecha, la izquierda es populista porque manipula a las clases medias y populares; para la izquierda, la derecha es populista porque manipula a las clases medias y populares (poco politizadas) con discursos que buscan generar la emoción más primitiva (el miedo)”. En la misma línea se sitúa Retamozo (2014: 227), para quien la dimensión discursiva del populismo ha estado siempre presente en América Latina. Para este autor, en un principio, el discurso populista estaba ligado a la intervención de un liderazgo carismático, aunque con el paso de los años se considera más como un liderazgo demagógico que en el campo del poder político tiene tendencias autoritarias y decisionistas.

Charaudeau (2009b) concibe el discurso populista como una estrategia de manipulación que maneja las mismas categorías que el discurso político, pero en exceso, un exceso que juega sobre la emoción en detrimento de la razón política. Esta estrategia se plasma en las cuatro características propias de un discurso populista, según el autor:

1. Descripción catastrófica de la situación social de la que es víctima el pueblo:

- Situación económica: habla sobre la crisis, insistiendo sobre las cargas sociales que pesan sobre las empresas, sobre las situaciones de precariedad de los trabajadores (desempleo, despidos) y sobre la disparidad entre ricos y pobres, o el empobrecimiento general de la nación. 
- Decadencia moral de la nación: habla de la pérdida de referencias identitarias, particularmente de la identidad nacional, de la pérdida de civismo y, por tanto, del relajamiento del vínculo social.

- Estado de victimización de los ciudadanos: habla de los «desclasados», los «subalternos», los «pequeños» (el «bajo pueblo» contra «los grandes»), víctimas de la inseguridad por falta de protección policial y de autoridad judicial.

2. Denuncia de los culpables de los males que sufre el país:

- La causa de los males del país es un sistema abstracto que bloquea a la sociedad: la clase política, las élites aisladas del pueblo, las instituciones políticas que han perdido toda autoridad, la burocracia.

- La causa de los males del país es el enemigo interior, representado por personas o grupos que aparecen como adversarios que hay que combatir por cuanto pertenecen a un grupo, un partido, una ideología: los marxistas, los socialistas, los capitalistas, los fascistas, etc., que son descritos como lobbies, mafias, grupos de interés u oligarquías.

- La causa de los males del país es el enemigo exterior, representado por una entidad abstracta con el fin de provocar miedo frente a una amenaza real o potencial: la inmigración, las personas o grupos extranjeros que desempeñan el papel de chivo expiatorio.

3. Exaltación de valores del país, valores que representan un vínculo que une a sus ciudadanos:

- Identidad nacional: utilizada para exhibir el fundamento de la identidad colectiva y la independencia económica como derecho a disponer de sus propios recursos, contra el explotador privado o extranjero que priva al pueblo de su bien «natural».

- Restablecimiento de la soberanía popular: promete otorgar al pueblo el poder de decisión y la redención por la liberación del yugo impuesto por las élites y los aparatos administrativo-políticos.

4. Aparición del salvador/a de la sociedad, un hombre/mujer providencial carismático, visionario, capaz de romper con el pasado:

- Representante del pueblo: el líder se presenta como el representante directo del pueblo, apropiándose incluso del pueblo en su propia figura.

- Ethos de autenticidad: trata de establecer una relación de confianza ciega entre el líder y las masas.

- Ethos de potencia: el líder quiere demostrar no solamente que tiene energía, sino que está dotado de una fuerza y de una potencia capaces de subvertir el mundo y arrastrar multitudes.

En nuestra época, el líder populista se presenta como un buen comunicador, un sujeto que demuestra un gran dominio de la oralidad, un hábil conector de lo real y lo simbólico, un 
intérprete y depositario de las aspiraciones de las culturas populares. En la medida en que las democracias tienen un mayor carácter de opinión-espectáculo que, de partidos, el populista se presenta preocupado por "dejarse ver" y por dar visibilidad en sus discursos a los marginados y descontentos (Elórtegui, 2009: 15-16). Los mensajes populistas intentan establecer una semejanza entre emisor y receptor, pero tal semejanza no se encuentra confirmada en el propio discurso populista (Britto, 2011: 75). El discurso del líder populista encuentra un aliado extraordinario en los medios de comunicación, gracias a los cuales puede trasladar a la opinión pública mensajes que defienden sus propuestas y atacan las contrarias. Los medios constituyen el "campo de batalla política donde definir estrategias, al estilo de ejércitos mediáticos organizados en forma centralizada que poseen un discurso homogéneo destinado a fortalecer al caudillo que está en el poder” (Rojas, Mujica y Suckel, 2009: 142).

En un análisis del populismo latinoamericano desde la perspectiva de la comunicación política, Rincón (2008: 5-6) considera que en América Latina se han sustituido los partidos por una fórmula de democracia que mezcla al héroe mediático -que tiene una personalidad carismática- con el populismo -entendido como el asistencialismo directo y la redención social del pueblo-pobre - y con el elitismo de economía liberal -el apoyo irrestricto a los empresarios y los nuevos ricos. Según este autor, este nuevo sistema se basa en el líder que gobierna dentro de un "autoritarismo light", casi farandulesco, que sabe estar cerca de los sentimientos y expectativas populares, pero lejos de la argumentación ideológica. Un líder que ha sido investido por los medios de comunicación, la historia y el pueblo para crear el paraíso prometido, que convence porque siempre está en pantalla.

\section{La comunicación del líder político}

Política y comunicación son dos conceptos consustanciales, en el sentido de que las acciones políticas que se ponen en marcha son difíciles que lleguen a buen puerto sin un adecuado proyecto de comunicación, sin un flujo de mensajes que surta determinados efectos (Rey, 1996: 52). La comunicación política, por tanto, es tan antigua como la política misma, aunque su ámbito de uso y de estudio han ido variando a lo largo del tiempo. Según Wolton (1998: 29), en un principio, la comunicación política designó al estudio de la comunicación entre el gobierno y el electorado, más tarde se aplicó al intercambio de discursos entre los políticos en el poder y los de la oposición, y más adelante se extendió al estudio del papel de los medios de comunicación masiva en la formación de la opinión pública y a la influencia de los sondeos en la vida política.

Perspectivas de la Comunicación - Vol. 13 - No 2 - 2020 - pp. 187-217

Universidad de la Frontera - Chile 
En la época actual, la perspectiva clásica se ha ampliado hacia un concepto que integra la información, la política y la comunicación, y que se ocupa del intercambio de discursos "entre los tres actores que tienen legitimidad para expresarse públicamente sobre política, que son los políticos, los periodistas y la opinión pública” (Wolton, 1998: 31). Este autor entiende la comunicación política como un espacio de confrontación de puntos de vista contradictorios entre estos tres actores, en el que es imprescindible la interacción entre sus tres discursos. Canel comparte esta idea de la implicación activa de todos los actores, de tal manera que, en la comunicación política, "los significados que se transfieren no son sólo el resultado de la acción de quien habla, sino del intercambio que se produce entre todos los implicados en el proceso" (2006: 27).

La comunicación es esencial en la actividad política tanto para acceder al poder como para mantenerse en el mismo. Los candidatos necesitan darse a conocer ante la ciudadanía para legitimar su autoridad y, una vez en el cargo, necesitan que las medidas que adoptan sean entendidas y asumidas para poder consolidar la legitimidad obtenida en las elecciones (Canel, 2006: 18-19). No se trata solo de que sean buenos políticos, también deben parecerlo, para lo cual necesitan convencer al mayor número posible de individuos de que son de fiar. Entendemos, así, la comunicación política como un acto persuasivo cuyo objetivo es convencer al público para que acepte la ideología que los líderes transmiten a través de discursos que dan énfasis a sus actuaciones y se lo restan a las actuaciones de sus adversarios y antecesores en el cargo (Dijk, 1999, 2003, 2005). Según esta concepción, el significado que se construye en el discurso político tiene una naturaleza interaccional, pero, además, posibilita la construcción de nuevas visiones del mundo a través de las cuales actuar sobre las visiones del público y, en consecuencia, controlar su manera de obrar (Castells, 2009: 24 y 33$)$.

Los discursos políticos están impregnados de una interpretación ideológica por parte de su emisor. Las manifestaciones de los líderes públicos se enmarcan en la disciplina de la retórica, que no es otra cosa que "el arte de la persuasión: el intento de un ser humano de influir en otro mediante palabras" (Leith, 2012: 13). La fuente que inicia el proceso comunicativo pretende producir un efecto en el receptor y modificar su conducta en algún sentido, su finalidad esencial es conseguir el apoyo del público, tratar de que acepte su verdad, con independencia de que objetivamente esa verdad se corresponda o no con la realidad. 
La retórica es una herramienta fundamental en las sociedades democráticas que basan su sistema político en el libre debate entre diferentes opciones ideológicas. Los discursos con finalidad persuasiva desempeñan un papel decisivo, porque a través de ellos se desarrolla la oposición entre las diferentes posturas presentes en la sociedad (Capdevila, 2004: 17). Así, el mensaje persuasivo, lejos de constituir un riesgo para la libertad, se vuelve imprescindible en la necesaria pluralidad, y su existencia es símbolo de una sociedad abierta. En este contexto, "el político es un comunicador que encuentra en la persuasión su instrumento más valioso" (Yanes, 2006: 61) y maneja en su discurso el vocabulario de la promesa y del cumplimiento de lo prometido (Gaspar e Ibeas, 2015: 43).

El contenido de los discursos persuasivos no hace referencia únicamente a una argumentación lógica, sino más bien a una puesta en escena persuasiva en la que ethos -la credibilidad del orador-y pathos -las emociones de los receptores-obtienen la mejor parte, dejándole al logos -los argumentos lógicos y racionales- la peor parte. Los líderes no deben establecer una verdad, sino conseguir tener la razón y hacer que la ciudadanía comparta esta razón, para lo cual necesitan llevar a cabo estrategias discursivas que traten de hacerlos más creíbles, para estar en situación de incitar a sus públicos a hacer, a decir o a pensar. Por ello, los políticos están más preocupados por el impacto de sus discursos que por el rigor de sus razonamientos (Charaudeau, 2009a: 278).

La inevitable carga ideológica y persuasiva en las declaraciones políticas no es un fenómeno reciente. Los grandes pensadores clásicos estudiosos de la retórica -como Aristóteles, Cicerón y Quintiliano- ya tenían claro que el discurso político era un acto persuasivo y sabían que su influencia radicaba más en cómo se decía que en lo que se decía. Demostraron que para convencer a los demás lo más importante era que el emisor del discurso inspirase confianza a sus oyentes y despertase en ellos emociones positivas, más incluso que el propio contenido de su exposición.

En nuestros días, "la comunicación política moderna sigue siendo retórica, pues busca, al igual que el discurso político tutelado por la retórica clásica, generar en el oyente efectos cognitivos que le muevan y persuadan a una acción social favorable al orador" (López y Santiago, 2000: 19). La diferencia de la época actual radica sobre todo en la omnipresencia de los medios de comunicación como interlocutores entre los líderes y la ciudadanía. Los políticos continúan utilizando la retórica para salir favorecidos ante los ojos de la gente, pero la cobertura que los medios ofrecen de sus discursos es crucial para la configuración de la 
imagen que de ellos se percibe. "La presencia de la cámara ahora es insidiosa y lo cambia todo. Nadie actúa delante de una cámara como si esta no estuviera. Y desde hace décadas está todo el tiempo. La convivencia de medios y políticos se vuelve promiscua y constante" (Arroyo, 2012: 363).

La sociedad actual se diferencia de todas las anteriores por la adopción del marketing y por la manera en que esta adopción afecta a la comunicación política. La creciente preocupación de los líderes políticos por la imagen que transmiten de ellos los medios ha hecho que la comunicación ya no solo sea un recurso para describir la realidad, sino que la antecede, la crea, de tal manera que, en nuestra sociedad mediática, la realidad es la comunicación (Rey, 2011: 110-111). Existe una interacción entre las agendas mediática y política, lo que hace del marketing político el gran instrumento que tienen al alcance los partidos para interactuar con el discurso de los medios de masas, para entrar en la disputa por establecer la agenda política, la pública y también la mediática (Aira, 2009: 23). La comunicación política entendida como marketing propicia una forma cortoplacista de entender la política, más centrada en seducir a la población mediante la transmisión de una imagen positiva del líder que le ayude obtener más votos y a perpetuarse en el poder -o a acceder a él- que en tomar decisiones que en el futuro permitan mejorar la vida de la ciudadanía. La política ya no busca educar, convencer e interactuar en la solución de los asuntos públicos, sino persuadir e inducir el comportamiento deseado de las masas votantes, que se convierten en consumidores de imágenes y eslóganes políticos (Salas-Porras, 2002: 118).

La teoría del framing o encuadre se refiere al proceso de selección de unos pocos elementos de la realidad percibida y construcción de una narrativa que destaque las conexiones entre ellos para promover una interpretación particular (Entman, 2007: 164). Este proceso de encuadre juega un papel crucial en el ejercicio de la política, ya que permite a las élites políticas ejercer poder sobre el público a través de la construcción selectiva de la realidad, enfatizando y omitiendo determinados aspectos en sus interpretaciones, lo que podría dirigir las reacciones del público hacia diferentes rumbos (Entman, 1993).

El concepto de framing ha cobrado una gran popularidad dentro del campo de la praxis de la comunicación política, sobre todo en Estados Unidos, donde se ha convertido en una de las herramientas más usadas de modo estratégico por los políticos para definir la realidad social según su propia conveniencia (Sádaba, Rodríguez y Bartolomé, 2012: 113). Liderar el modo en que se encuadran los asuntos políticos es de vital importancia para establecer los 
términos en los que se desarrollará el debate público, por eso los políticos intentan poner en marcha mecanismos estratégicos para construir la realidad según sus intereses. "La concepción estratégica del framing se asienta sobre la premisa de que definir la realidad con unas u otras palabras lleva a diferentes universos de discurso que promueven diferentes juicios, actitudes y conductas entre los receptores” (Sádaba, Rodríguez y Bartolomé, 2012: 115), por eso se presta gran atención al lenguaje con el que los políticos hablan de los asuntos públicos para definirlos según les conviene, influyendo a través de sus palabras en el comportamiento de la ciudadanía. El modelo de respuesta en cascada de Entman (2003, 2004) jerarquiza a los diferentes actores de la comunicación política en función de su poder para ofrecer frames o encuadres que dominen la interpretación de determinados asuntos. Según este modelo, el presidente ocupa el primer nivel entre los diferentes actores políticos, por lo que tiene el poder para decidir qué asociaciones mentales quiere activar en sus públicos a través de sus discursos.

\section{Objetivos y metodología}

El presente artículo tiene como objetivo general analizar los dos discursos ofrecidos por Cristina Fernández de Kirchner con motivo de sus tomas de posesión -el pronunciado el 11 de diciembre de 2007 en su toma de posesión como presidenta de la República Argentina y el pronunciado el 10 de diciembre de 2011 en la asunción de su segundo mandato-, para indagar en la estrategia comunicativa que empleaba en sus disertaciones públicas. A partir de este objetivo general, hemos establecido cuatro objetivos específicos: a) identificar las características populistas que se manifiestan en dichos discursos, de acuerdo con los conceptos propuestos por Charaudeau (2009b); b) comprobar cómo se califica la Presidenta a sí misma, es decir, cuál es la imagen que transmitió de sí misma en sus actos de investidura; c) comprobar cómo califica al público receptor de sus discursos; y d) comparar las características que la Mandataria menciona de sí misma con las que atribuye a su pueblo.

A partir de los objetivos mencionados, se plantearon las siguientes hipótesis de trabajo: H1.- En el discurso de Cristina Fernández de Kirchner como presidenta de Argentina aparecen de forma repetida las características del estilo populista y destaca con mayor presencia la estrategia de presentarse a sí misma como mujer providencial y carismática, salvadora de la sociedad.

H2.- En el discurso de Cristina Fernández cobran una gran importancia las referencias a su identidad, ya sea autocalificándose o definiendo su hacer. Dichas referencias son siempre positivas y se refieren a una líder honesta y activa.

Perspectivas de la Comunicación - Vol. 13 - No 2 - 2020 - pp. 187-217

Universidad de la Frontera - Chile 
H3.- Las alusiones a los sujetos receptores son mucho menos frecuentes que las referencias a ella misma. En su mayoría tienen un matiz negativo, ya que presentan al pueblo como un sujeto pasivo y receptivo.

H4.- La imagen que la presidenta transmite de sí misma no se corresponde con la que transmite de su pueblo, por lo que no se produce esa semejanza entre emisor y receptor que es propia de los discursos populistas.

Para conseguir los objetivos planteados y ratificar o refutar estas hipótesis, se empleó el método del análisis de contenido cuantitativo y cualitativo, "un conjunto de técnicas de análisis de las comunicaciones utilizando procedimientos sistemáticos y objetivos de descripción del contenido de los mensajes" (Bardin, 2002: 29). El análisis de contenido cualitativo busca la presencia o ausencia de características y temas en un mensaje, describe sus particularidades, establece las categorías y las interpreta; y el análisis de contenido cuantitativo se sustenta en el recuento, por lo que el valor o la importancia de los contenidos se establece como resultado de la frecuencia con la que aparecen las unidades informativas o de significación (Bardin, 2002: 29; Báez, 2007: 290).

No es tarea de este trabajo abordar el populismo como doctrina ideológica, sino como una serie de recursos discursivos que se basan en la oposición entre el pueblo y el poder (Laclau, 2005). Por ello, el objeto de estudio es el discurso de la presidenta de un país, quien, como tal, ocupa un lugar privilegiado para persuadir a los ciudadanos con la intención de lograr una actitud favorable hacia ella, con el objeto de inducirlos hacia determinadas conductas y comportamientos. El análisis de contenido se llevó a cabo desde la teoría del framing.

El primero de los discursos analizados tiene una extensión total de 4.436 palabras, divididas en 54 párrafos. El segundo discurso está compuesto por 7.514 palabras, divididas en 85 párrafos. En total, se han analizado 139 párrafos, que contienen 11.950 palabras.

Con el objeto de sistematizar el contenido de los discursos analizados, en primer lugar, se han distinguido cuatro categorías o frames, y se ha identificado cuál es la categoría dominante en cada uno de los párrafos de los discursos. Dichas categorías se corresponden con los conceptos empleados por Charaudeau (2009b) para establecer las cuatro características propias de un discurso populista: Descripción catastrófica de la situación social, Denuncia de los culpables, Exaltación de valores del país y Aparición del salvador/a de la sociedad. 
Por otro lado, se han cuantificado las veces que la presidenta se menciona a sí misma explícitamente en cada uno de los discursos, bien sea como mandataria, como partido, o como gobierno, y se han identificado las características que se atribuye en cada una de las menciones. Además, se han contabilizado las veces que la presidenta menciona explícitamente a sus receptores, y se ha identificado la forma en la que califica a dichos receptores cuando se refiere a ellos como pueblo.

\section{Resultados}

\section{Características del discurso populista}

En el conjunto de los dos discursos, se ha encontrado que Cristina Fernández utiliza continuamente, prácticamente en la totalidad de los párrafos analizados, alguna de las cuatro categorías que Charaudeau (2009b) expone como características de los discursos populistas. Tal y como se refleja en el Gráfico 1, la categoría mayoritaria es la de Aparición de la salvadora de la sociedad, presente en el 48,92\% de los párrafos. Las otras tres categorías aparecen a gran distancia de la primera: en el 22,3\% de los párrafos hace una exaltación de valores del país, en el 16,55\% denuncia a los culpables por los males que sufre su país, y en el 11,51\% describe de manera catastrófica la situación social de la que es víctima el pueblo.

Gráfico 1. Características del discurso populista (\% de los párrafos totales)

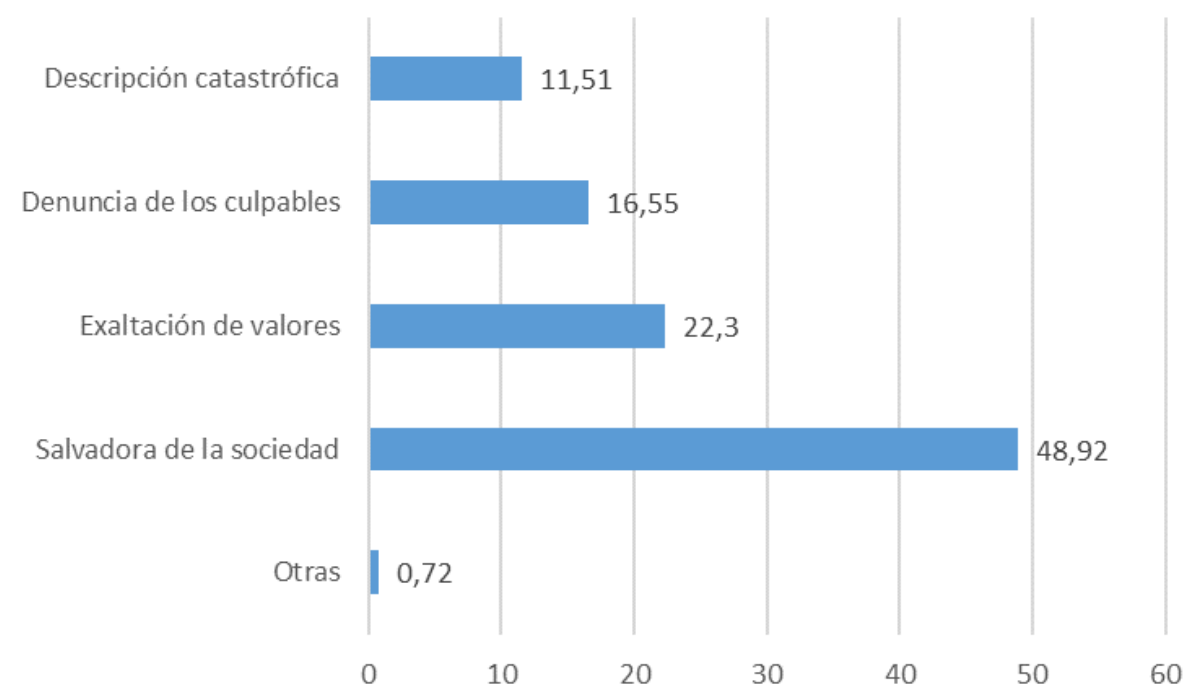

Fuente: Elaboración propia 
Si desglosamos estas características (Gráfico 2), podemos observar que dentro de la categoría de Salvadora de la sociedad -que es la predominante en los discursos analizadosdominan claramente las alusiones de la presidenta a sí misma como Representante directa del pueblo (40,29\%). Ejemplos de este tipo de alusiones son los siguientes:

- [...] hemos fructificado uniéndonos a hombres y mujeres de distinta pertenencia partidaria con un solo objetivo: cumplir con el mandato popular. No nos votan para que nos peleemos entre nosotros. Nos votan para que trabajemos por ellos, los ciudadanos y las ciudadanas. (Discurso 1).

- Y llegó ya, durante nuestra gestión, y bajo la égida del exministro de Economía y del actual ministro de Economía, por instrucciones de esta presidenta, la segunda parte de la reestructuración de la deuda, que nos llevó a cubrir ya el 93 por ciento. (Discurso 2).

Dentro de la característica de Exaltación de valores, la subcategoría dominante es la de Identidad nacional (17,99\%), que se refleja en fragmentos como estos:

- Ese es el país que tenemos que reconstruir los argentinos, reconociéndonos -es cierto- en nuevos instrumentos y en nuevas políticas, porque vivimos también en un mundo diferente y de esto finalmente es de lo que quiero hablar, de nuestra inserción en el mundo. (Discurso 1).

- [...] hoy tenemos un país que ha tenido el período de crecimiento más largo de sus 200 años de historia. Que, además, su Producto Bruto ha sido per cápita uno de los más importantes, sino el más importante del mundo, en materia de crecimiento, superado por el nivel de industrialización. Porque el nivel de actividad económica, que ha crecido a tasas chinas, sin embargo, ha sido superado por el nivel de crecimiento de la industria y una cosa no está desligada de la otra, al contrario, está perfectamente articulado. (Discurso 2).

En lo que se refiere a la característica de Denuncia de los culpables, destaca la alusión al Enemigo exterior como causa de los males del país $(8,63 \%)$, que se observa en ejemplos como los siguientes:

- $\quad$ [...] pero también con la misma sinceridad quiero decirle que esta situación que hoy atravesamos no nos es imputable. Porque más allá de medidas que muchas veces podemos no compartir, lo cierto es que nosotros nos hemos presentado en la Corte Internacional de La Haya porque se ha violado el Tratado del Río Uruguay al instalar las pasteras. (Discurso 1).

- $\quad$ [...] lo que es más importante es que hemos podido hacer esto en un período [...] con un mundo en contra, fuera del mercado de capitales, que, para nosotros, paradojalmente, fue una bendición porque impidió que se inyectara a nuestro sistema financiero activos tóxicos como pasó. (Discurso 2). 
Por último, en la característica de Descripción catastrófica de la situación social -la que menos presencia tiene en los discursos- sobresalen las menciones a la mala Situación económica $(7,19 \%)$, que se pueden observar en fragmentos como los siguientes:

- [...] cuando se producen brechas de equidad en la sociedad son precisamente los sectores más vulnerables, los más pobres los que van a la escuela pública. (Discurso 1).

- La Argentina ha dado un salto fenomenal desde aquella Argentina en la que él asumiera con el $22 \%$ de los votos, el 25\% de desocupación, un cuarto de la población argentina, 11.00o millones en el Banco Central de reservas, más del 140\% de nuestro Producto Bruto Interno comprometido en deuda, con más del 54\% de nuestra población sumida en la pobreza y más del 25 sumida en la indigencia, con una desindustrialización formidable que hacía, por ejemplo, obreros de la Unión Obrera Metalúrgica marcharan junto a los propietarios de las empresas reclamando la industrialización del país [...] (Discurso 2).

Gráfico 2. Características del discurso populista desglosadas (\% de los párrafos totales)

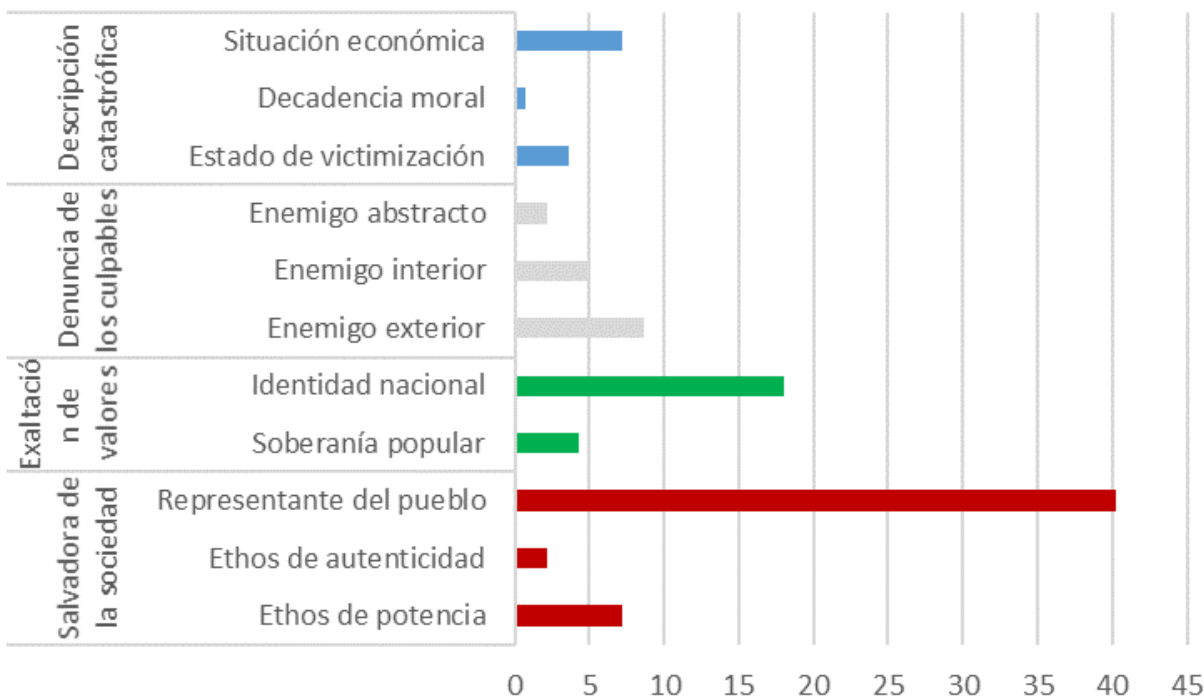

Fuente: Elaboración propia

Atendiendo a los dos discursos por separado, podemos comprobar las diferencias y semejanzas que existen entre ambos, reflejadas en la tabla 1 : 
Tabla 1. Características del discurso populista desglosadas (por discurso)

\begin{tabular}{|c|c|c|c|c|c|c|c|}
\hline \multirow{2}{*}{ Categorías } & \multirow{2}{*}{ Subcategorías } & \multicolumn{2}{|c|}{ Discurso 1} & \multicolumn{2}{|c|}{ Discurso 2} & \multicolumn{2}{|c|}{ Discursos 1 y 2} \\
\hline & & Total & $\%$ & Total & $\%$ & Total & $\%$ \\
\hline \multirow{3}{*}{ Salvadora de la sociedad } & Ethos de potencia & 4 & 7,41 & 6 & 7,14 & 10 & 7,25 \\
\hline & Ethos de autenticidad & 2 & 3,70 & 1 & 1,19 & 3 & 2,17 \\
\hline & Representante del pueblo & 18 & 33,33 & 38 & 45,24 & 56 & 40,58 \\
\hline \multirow{2}{*}{ Exaltación de valores } & Soberanía popular & 2 & 3,70 & 4 & 4,76 & 6 & 4,35 \\
\hline & Identidad nacional & 11 & 20,37 & 14 & 16,67 & 25 & 18,12 \\
\hline \multirow{3}{*}{ Denuncia de los culpables } & Enemigo exterior & 5 & 9,26 & 7 & 8,33 & 12 & 8,70 \\
\hline & Enemigo interior & 1 & 1,85 & 6 & 7,14 & 7 & 5,07 \\
\hline & Enemigo abstracto & 2 & 3,70 & 1 & 1,19 & 3 & 2,17 \\
\hline \multirow{3}{*}{ Descripción catastrófica } & Estado de victimización & 4 & 7,41 & 1 & 1,19 & 5 & 3,62 \\
\hline & Decadencia moral & 1 & 1,85 & o & 0,00 & 1 & 0,72 \\
\hline & Situación económica & 4 & 7,41 & 6 & 7,14 & 10 & 7,25 \\
\hline \multicolumn{2}{|c|}{ TOTAL } & 54 & 100 & 84 & 100 & 138 & 100 \\
\hline
\end{tabular}

Fuente: Elaboración propia

Los resultados son similares en la mayoría de las características en los dos discursos analizados. Las dos principales diferencias consisten en:

- Un notable aumento del peso de la categoría de Salvadora de la sociedad en el Discurso 2 (53,57\% frente al 44,44\% en el Discurso 1), diferencia que se refleja básicamente en la subcategoría de Representante del pueblo, que aumenta de un 33,33\% en el Discurso 1 a un 45,24\% en el Discurso 2.

- Una notable reducción del peso de la categoría de Descripción catastrófica de la situación en el Discurso 2 (8,33\% frente al 16,67\% en el Discurso 1), plasmada sobre todo en la disminución del peso de la subcategoría de Estado de victimización, que pasa de un 7,41\% en el Discurso 1 a un 1,19\% en el Discurso 2.

En menor medida, se observa una reducción en la categoría de Exaltación de valores, que pasa de un 24,07\% en el Discurso 1 a un 21,43\% en el Discurso 2, y un ligero aumento de 
Denuncia de los culpables, que pasa de un 14,81\% en el Discurso 1 a un 16,67\% en el Discurso 2.

\section{Referencias a sí misma y a los sujetos receptores}

En lo que se refiere a la cantidad de veces que Cristina Fernández se menciona de forma explícita a sí misma y menciona explícitamente al pueblo como receptor, se ha cuantificado un total de 319 menciones. De ellas, 228 (71,47\%) son automenciones de la presidenta y 91 $(28,53 \%)$ son menciones al público receptor de los mensajes. Es decir, la líder se menciona a sí misma más del doble de veces que las que menciona a su pueblo. El porcentaje se mantiene similar si comparamos las menciones de los dos discursos, tal y como se refleja en el Gráfico 3:

Gráfico 3. Número de menciones a sí misma y a los sujetos receptores

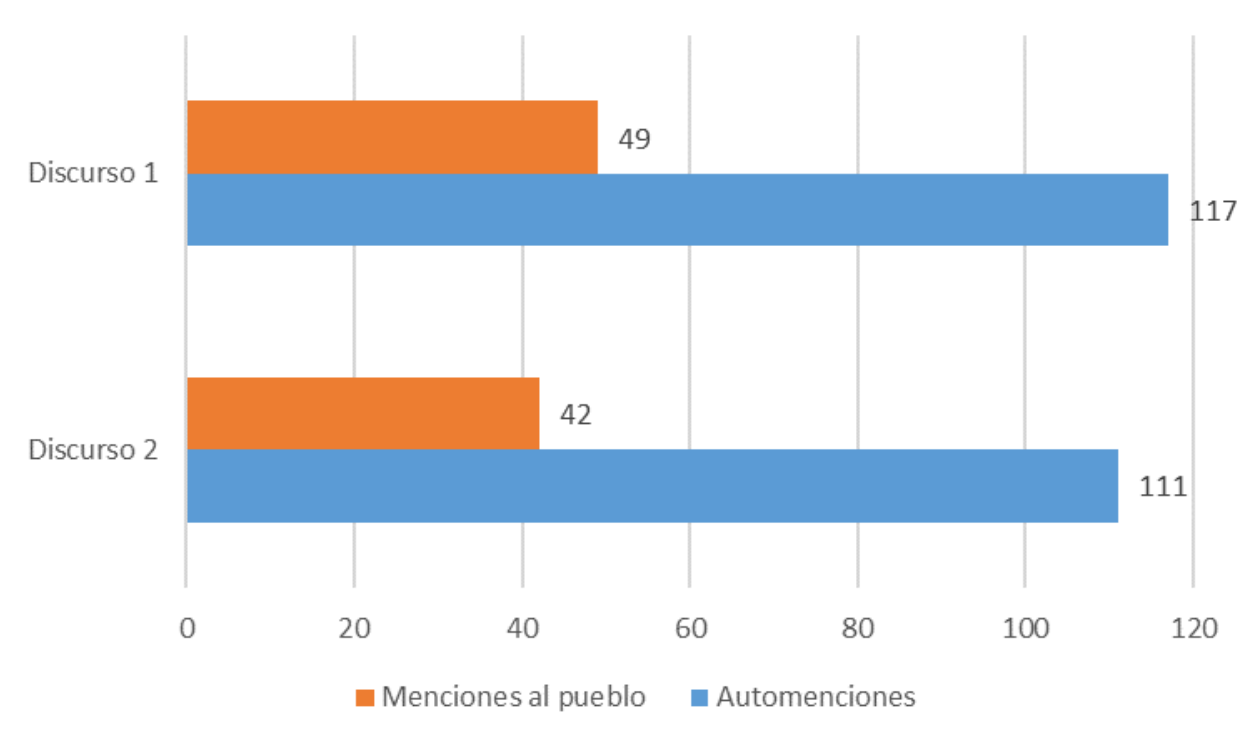

Fuente: Elaboración propia

En el Discurso 1 hay un total de 166 menciones, de las cuales 117 (70,48\%) son a sí misma y 49 (29,52\%) a los receptores. En el Discurso 2 aparecen 153 menciones: 111 (72,55\%) se refieren a sí misma y $42(27,45 \%)$ a su pueblo. Llama la atención que el número de menciones (tanto automenciones como menciones a los receptores) disminuye en el Discurso 2 con respecto al Discurso 1, si tenemos en cuenta que el segundo discurso tiene una extensión muy superior al primero (4.436 palabras el Discurso 1, 7.514 palabras el 
Discurso 2). De manera superficial, puede parecer que este es un síntoma de que el segundo discurso fue más abierto y diverso que el primero, en lo que a los sujetos protagonistas de los mensajes emitidos se refiere.

En lo que se refiere al aspecto cualitativo de las menciones que aparecen en los discursos, podemos decir que en la práctica la totalidad de las automenciones (97,37\%) Cristina Fernández se presenta a sí misma con cualidades que la definen como un sujeto activo, mientras que para definir al pueblo receptor de los discursos utiliza cualidades que lo definen como sujeto activo tan solo en un $37,36 \%$ de las menciones y como sujeto pasivo en un $62,64 \%$. Las Tablas 2 y 3 reflejan el tipo de cualidades que la presidenta se asigna a sí misma y las que asigna a los receptores. 
Tabla 2. Cualidades que se atribuye la presidenta en las automenciones

\begin{tabular}{|c|c|c|}
\hline Cualidades & Total & $\%$ \\
\hline Resolvedora de problemas & 81 & 35,53 \\
\hline Defensora del pueblo & 20 & 8,77 \\
\hline Colaboradora con otros partidos o ideas & 11 & 4,82 \\
\hline Con convicciones & 11 & 4,82 \\
\hline Ganadora de elecciones & 10 & 4,39 \\
\hline Cumplidora de la voluntad del pueblo & 9 & 3,95 \\
\hline Agradecida & 8 & 3,51 \\
\hline Luchadora & 7 & 3,07 \\
\hline Defensora de las instituciones & 6 & 2,63 \\
\hline Trabajadora & 6 & 2,63 \\
\hline Defensora de los derechos humanos & 5 & 2,19 \\
\hline Esperanzada & 5 & 2,19 \\
\hline Miembro del pueblo & 5 & 2,19 \\
\hline Orientadora & 5 & 2,19 \\
\hline Víctima & 5 & 2,19 \\
\hline Democrática & 4 & 1,75 \\
\hline Pide colaboración al pueblo & 4 & 1,75 \\
\hline Honesta & 3 & 1,32 \\
\hline Líder & 3 & 1,32 \\
\hline Fanática de la ciencia y tecnología & 2 & 0,88 \\
\hline Humilde & 2 & 0,88 \\
\hline Patriota & 2 & 0,88 \\
\hline Promotora del ascenso social & 2 & 0,88 \\
\hline Representante del pueblo & 2 & 0,88 \\
\hline Triunfadora & 2 & 0,88 \\
\hline Valiente & 2 & 0,88 \\
\hline Comete errores & 1 & 0,44 \\
\hline Defensora de las grandes empresas & 1 & 0,44 \\
\hline Militante & 1 & 0,44 \\
\hline Moderna & 1 & 0,44 \\
\hline
\end{tabular}




\begin{tabular}{|l|c|c|}
\hline Muestra emociones & 1 & 0,44 \\
\hline Reflexiva & 1 & 0,44 \\
\hline TOTAL & 228 & 100,01 \\
\hline
\end{tabular}

Fuente: Elaboración propia

La presidenta se presenta a sí misma sobre todo como resolvedora de problemas (35,53\% de las automenciones), dato que concuerda con la categoría de Aparición de la salvadora de la sociedad, dominante en los discursos analizados. No obstante, Cristina Fernández va más allá del papel de guía del pueblo y salvadora profética que define Charaudeau (2009b), y se muestra cercana a los problemas reales de la gente. A gran distancia les siguen las automenciones que la definen como defensora del pueblo $(8,77 \%)$, colaboradora con otros partidos o ideas $(4,82 \%)$, persona con convicciones $(4,82 \%)$, ganadora de elecciones (4,39\%), cumplidora de la voluntad del pueblo (3\%), agradecida $(3,51 \%)$ y luchadora $(3,07 \%)$, entre otras muchas cualidades positivas. 
Tabla 3. Cualidades que atribuye la presidenta al pueblo-receptor

\begin{tabular}{|c|c|c|}
\hline Cualidades & Total & $\%$ \\
\hline Receptor de políticas públicas & 13 & 14,29 \\
\hline Receptor de mensajes & 10 & 10,99 \\
\hline Necesitado & 7 & 7,69 \\
\hline Contribuye a la sociedad & 5 & 5,49 \\
\hline Próspero & 5 & 5,49 \\
\hline Representado por el gobierno & 5 & 5,49 \\
\hline Votante & 5 & 5,49 \\
\hline Acompaña al gobierno & 4 & 4,40 \\
\hline Diligente & 4 & 4,40 \\
\hline Incumple sus obligaciones & 3 & 3,30 \\
\hline Luchador & 3 & 3,30 \\
\hline Protegido & 3 & 3,30 \\
\hline Débil & 2 & 2,20 \\
\hline Desocupado & 2 & 2,20 \\
\hline Ignorado & 2 & 2,20 \\
\hline Ignorante & 2 & 2,20 \\
\hline Improductivo & 2 & 2,20 \\
\hline Inculto & 2 & 2,20 \\
\hline Víctima & 2 & 2,20 \\
\hline Con convicciones & 1 & 1,10 \\
\hline Disfruta & 1 & 1,10 \\
\hline Evasor de impuestos & 1 & 1,10 \\
\hline Fracasado & 1 & 1,10 \\
\hline Inestable & 1 & 1,10 \\
\hline Intranquilo & 1 & 1,10 \\
\hline Parte del Estado & 1 & 1,10 \\
\hline Patriota & 1 & 1,10 \\
\hline Privilegiado & 1 & 1,10 \\
\hline Trabajador & 1 & 1,10 \\
\hline TOTAL & 91 & 100,00 \\
\hline
\end{tabular}


Por otro lado, Cristina Fernández presenta al pueblo principalmente como un sujeto pasivo, sobre todo como receptor de políticas públicas (14,29\%) y como receptor de los mensajes del gobierno (10,99\%), y también como necesitado (7,69\%), aunque en menor medida también le atribuye algunas cualidades activas: que contribuye a la sociedad $(5,49 \%)$ y que es próspero $(5,49 \%)$. Vemos, pues, que la mayoría de las atribuciones que la presidenta hace de sí misma no coinciden con las que hace de los receptores de sus discursos, ya que su autoimagen la conforma con características activas y positivas, mientras que la imagen que ofrece de su pueblo es fundamentalmente de personas pasivas y con cualidades negativas.

\section{Discusión y conclusiones}

Teniendo en cuenta que Cristina Fernández de Kirchner evitaba que los medios de comunicación realizaran la labor de intermediación entre ella y la ciudadanía, a menudo sus palabras llegaban directamente al público, sin pasar por la interpretación (por el frame) de los periodistas. De esta manera, sus discursos constituyen el principal cauce de comunicación con los ciudadanos. Es por esto, por lo que consideramos que el análisis de los dos discursos de toma de posesión constituye una importante fuente de información para conocer el estilo comunicativo de la presidenta, y determinar cuáles son los marcos o frames que establecía en los mensajes que enviaba a su país.

La estrategia comunicativa utilizada por Cristina Fernández en sus dos discursos de toma de posesión como presidenta de Argentina está marcada por un estilo discursivo que se ajusta a las características del estilo populista y por la transmisión de una imagen de sí misma como una líder carismática y representante directa del pueblo. En los dos discursos analizados se identifican de manera reiterada todas las características que, según el autor al que hemos recurrido, califican a un discurso como populista, con una pretensión clara de ahondar profundamente en los sentimientos de la población. De estas características, destaca especialmente la categoría en la que la presidenta se presenta como una mujer providencial y salvadora de la sociedad. La líder política, al dirigirse a las masas, busca que el público se adhiera a un proyecto o a una acción, busca disuadirle de seguir un proyecto adverso, señalando la fuente del mal encarnada en un adversario, y la solución salvadora encarnada en la oradora (Charaudeau, 2009a: 289). Se confirma, así, la primera de las hipótesis planteadas (H1), a través de una conclusión que refuerza las planteada por otros autores que 
han analizado otros discursos de la mandataria (Retamozo, 2014; Amado, 2015; Gindin, 2016).

Mostrarse ante la ciudadanía como salvador/a de la sociedad de manera recurrente es una de las técnicas más utilizadas entre los líderes populistas. Generalmente, este tipo de representante tiende a exagerar continuamente sus ideales, sus convicciones, expresando su punto de vista con una fuerza extrema, que cala profundamente en los oyentes. En los dos discursos analizados, la mayor parte del tiempo se emplea en transmitir la imagen de Cristina Fernández como salvadora de la sociedad, manifestando reiteradamente que todas sus acciones son llevadas a cabo por sus “convicciones”, por sus “ideales”. Esta categoría de salvadora de la sociedad tiene una mayor presencia en el segundo discurso que en el primero, lo que resulta coherente con el hecho de que la primera vez que se presentó al cargo sustituía al que fuera su marido, por lo que no le interesaba presentarse como salvadora de la gestión que él llevó a cabo. Así, no se presenta tanto como rompedora con el pasado sino como representante directa del pueblo, que exhibe las características históricas, identitarias y culturales propias frente al enemigo exterior.

La mandataria presenta una imagen de poder y fuerza, y busca hacerlo de la forma más convincente posible. Según Charaudeau (2009b: 268), esto se logra cuando la líder política expresa "lo profundo de su personalidad, ese algo irracional que se llama carisma". Esta imagen se ve reflejada en los dos discursos de Cristina Fernández de Kirchner, quien aparece representada como la esperanza del pueblo, comprometida con todos los ciudadanos, aunque la imagen va perdiendo cierto peso en sus intervenciones a lo largo del periodo analizado. De esta manera, se confirma también la segunda de las hipótesis planteadas (H2), según la cual las autorreferencias de la presidenta tienen una presencia muy importante en sus discursos y siempre son positivas.

Otra conclusión que se puede extraer de esta investigación apunta a que Cristina Fernández se automenciona a sí misma con mucha mayor frecuencia de la que menciona al pueblo como receptor. Esto implica que la líder-emisora se atribuye una importancia superior a la que atribuye al receptor del mensaje, por lo que habla ante todo de sí misma: para el populista 'el mensaje soy yo' (Britto, 2011: 76). La líder elabora un discurso que la presenta como portadora de características que ella valora y como símbolo de los valores con los que se identificará el pueblo (Arroyas y Pérez, 2016: 58). Esta idea se refuerza al reparar en el tipo de cualidades que la presidenta se asigna a sí misma y las que asigna a los receptores, ya que 
la totalidad de automenciones se refieren a cualidades activas, mientras que en las menciones al pueblo predominan las cualidades pasivas. No se observa correspondencia entre las características positivas que se atribuye a sí misma y las que atribuye a su pueblo. "La mayoría de las atribuciones que hace a los receptores no corresponden a la realización de valores, sino a estados de carencia, de pasividad o de mera recepción de bienes de consumo o auxilio" (Britto, 2011: 80). Por tanto, quedan también confirmadas la tercera y la cuarta hipótesis ( $\mathrm{H}_{3}$ y $\mathrm{H}_{4}$ ) y se refuta una idea muy extendida en anteriores investigaciones que indica que los mensajes populistas intentan establecer una semejanza entre emisor y receptor, ya que tal semejanza no se encuentra confirmada en el propio discurso populista (Britto, 2011: 75). 


\section{Referencias bibliográficas}

AIRA, T. (2009): Los Spin Doctors. Cómo mueven los hilos los asesores de los líderes políticos. Barcelona: Editorial UOC.

AMADO, A. (2015): Calidad periodística y fuentes presidenciales: el periodismo argentino frente a la comunicación de gobierno. Estudios sobre el Mensaje Periodístico, v. 21, pp. 6384. DOI: http://dx.doi.org/10.5209/rev_ESMP.2015.v21.50656

ARROYAS, E. y PÉREZ, P. L. (2016): La nueva narrativa identitaria del populismo: un análisis del discurso de Pablo Iglesias (Podemos) en Twitter. Cultura, lenguaje y representación, v. 15, pp. 51-63. DOI: http://dx.doi.org/10.6035/clr.2016.15.4

ARROYO, L. (2012): El poder político en escena. Historia, estrategias y liturgias de la comunicación política. Barcelona: RBA Libros.

BÁEZ, J. (2007): Investigación cualitativa. Pozuelo de Alarcón: ESIC.

BARDIN, L. (2002): Análisis de contenido. Madrid: Akal.

BERMÚDEZ, N. (2014): Las emociones en el discurso político. 'Pathograma' del kirchnerismo. Acta poética, 35 (1), pp. 11-43.

BIGLIERI, P. y PERELLÓ, G. (Eds.) (2007): En el Nombre del Pueblo: la emergencia del populismo kirchnerista. Buenos Aires: UNSAM Edita.

BRITTO, L. (2011): La máscara del poder. Del gendarme necesario al demócrata necesario. Caracas: Correo del Orinoco.

CANEL, M. J. (2006): Comunicación Política. Un guía para su estudio y práctica. Madrid: Tecnos.

CAPDEVILA, A. (2004): El discurso persuasivo: la estructura retórica de los espots electorales en televisión. Bellaterra: Universitat Autónoma de Barcelona. 
CASERO, A. (2009): El control político de la información periodística. Revista Latina de Comunicación Social, no. 64. Disponible en:

http://www.revistalatinacs.org/o9/art/29_828_47_ULEPICC_o8/Andreu_Casero.html

CASTELLS, M. (2009): Comunicación y poder. Madrid: Alianza Editorial.

CHARAUDEAU, P. (2009a): La argumentación persuasiva. El ejemplo del discurso político. En SHIRO, M., BENTIVOGLIO, P., ERLICH, FRANCES D. DE y BOLÍlVAR, A.: Haciendo discurso. Homenaje a Adriana Bolívar. Caracas: Universidad Central de Venezuela, pp. 277-304. Disponible en: http://www.patrick-charaudeau.com/Laargumentacion-persuasiva-El.html

(2009b): Reflexiones para el análisis del discurso populista. Discurso \& Sociedad, 3 (2), pp. 253-279. Disponible en:

http://www.dissoc.org/ediciones/vo3no2/DS3\%282\%29Charaudeau.pdf

DIEGO, J. (2014): ¿Discurso político o politicidad de los discursos? Una propuesta para pensar la relación entre kirchnerismo y prensa. En GINDIN, I. L. (Coord.): Kirchnerismo, mediatización e identidades políticas: reflexiones en torno a la política, el periodismo y el discurso (2003-2008), pp. 12-31. Rosario: UNR Editora.

DIJK, T. A. (1999): Ideología. Una aproximación interdisciplinaria. Barcelona: Gedisa. (2003): Ideología y discurso. Barcelona: Ariel. (2005): Política, ideología y discurso. Quórum Académico, 2 (2), pp. 15-47.

DUSSEL, E. (2007): Cinco tesis sobre “el populismo”. México: UAM-Iztapalapa.

ELÓRTEGUI, C. D. (2009): Populismos latinoamericanos y comunicación. Una nueva mirada a las interacciones de la política popular desde el caso chileno. Tesis doctoral. España, Universidad Autónoma de Barcelona. Disponible en: www.tdx.cat/bitstream/10803/4213/1/ceg1de1.pdf 
ENTMAN, R. (1993): Framing: Towards a Clarification of a Fractured Paradigm. Journal of Communication, 43 (4), pp. 51-58. DOI: http://dx.doi.org/10.1111/j.14602466.1993.tbo1304.x

(2003): Cascading Activation: Contesting the White House's Frame After 9/11. Political Communication, 20 (4), 415-432. DOI: $10.1080 / 10584600390244176$

(2004): Projections of Power: Framing News, Public Opinion, and U.S. Foreign Policy. Chicago: University of Chicago Press.

(2007): Framing Bias: Media in the Distribution of Power. Journal of Communication, 57 (1), pp. 163-173. DOI: 10.1111/j.1460-2466.2006.00336.x

FERNÁNDEZ, M. (2014): Periodismo y política en la Argentina kirchnerista: disputas por la intermediación en el espacio público. Un análisis desde la perspectiva de la mediatización. En GINDIN, I. L. (Coord.): Kirchnerismo, mediatización e identidades políticas: reflexiones en torno a la política, el periodismo y el discurso (2003-2008), pp. 1231. Rosario: UNR Editora.

GASPAR, A. e IBEAS, N. (2015): El discurso institucional en tiempos de crisis: análisis del Mensaje de Navidad de Su Majestad el Rey. ZER. Revista de Estudios de Comunicación, 20 (38), pp. 31-48.

GINDIN, I. L. (2016): Los avatares del pasado en el discurso de Cristina Fernández: Peronismo y Bicentenario. Opción, 31 (79), pp. 86-107.

DOI: http://dx.doi.org/10.5209/rev_ESMP.2015.v21.50656

LACLAU, E. (1978): Política e ideología en la teoría marxista. Capitalismo, fascismo, populismo. Madrid: Siglo XXI.

(2005): La razón populista. Buenos Aires: S. L. Fondo de Cultura Económica de España.

(2006): La deriva populista y la centroizquierda latinoamericana. Nueva Sociedad, no. 205 , pp. 56-61. 
LEITH, S. (2012): ¿Me hablas a mí? La retórica de Aristóteles a Obama. Madrid: Taurus.

LODOLA, G. y KITZBERGER, P. (2017): Politización y confianza en los medios de comunicación: Argentina durante el kirchnerismo. Revista de Ciencia Política, 37 (3), pp. 635-658.

LÓPEZ, A. y SANTIAGO, J. (2000): Retórica y comunicación política. Madrid: Cátedra.

MAZZOLENI, G. (2010): La comunicación política. Barcelona: Alianza Editorial.

MONTERO, A. S. (2009): Puesta en escena, destinación y contradestinación en el discurso kirchnerista (Argentina, 2003-2007). Discurso \& Sociedad, 3 (2), pp. 316-347.

NOVARO, M. (2006): Izquierda y populismo en la política argentina. En PÉREZHERRERO, P.: La izquierda en América Latina. Madrid: Instituto Universitario Ortega y Gasset y Fundación Pablo Iglesias, pp. 115-190. Disponible en: http://historiapolitica.com/datos/biblioteca/novaro2.pdf

O’DONNELL, M. (2008): El atril del asesino. En RINCÓN, O.: Los tele-presidentes: cerca del pueblo, lejos de la democracia. Crónicas de 12 presidentes latinoamericanos y sus modos de comunicar. Bogotá: Centro de Competencia en Comunicación para América Latina Friedrich Ebert Stiftung, pp. 39-45.

RETAMOZO, M. (2014): Populismo en América Latina: desde la teoría hacia el análisis político. Discurso, sujeto e inclusión en el caso argentino. Colombia Internacional, no. 82, pp. 221-258. DOI: 10.7440/colombiaint82.2014.09

REY, J. (1996): ¿De qué hablamos cuando hablamos de comunicación política? ZER. Revista de Estudios de Comunicación, no. 1, pp. 51-66.

(2011): La comunicación política en la sociedad del marketing y de internet. Encuadres, relatos y juegos de lenguaje. Revista de Comunicación, no. 10, pp. 102-128. 
RINCÓN, O. (2008): ¿La comunicación no tiene ideología? En RINCÓN, O.: Los telepresidentes: cerca del pueblo, lejos de la democracia. Crónicas de 12 presidentes latinoamericanos y sus modos de comunicar. Bogotá: Centro de Competencia en Comunicación para América Latina Friedrich Ebert Stiftung, pp. 5-13.

ROJAS, C., MUJICA, S. y SUCKEL, Á. (2009): Neopopulismo y el papel de los medios de comunicación en los gobiernos de Carlos Menem y Alberto Fujimori. Revista Pléyade, no. 3, pp. 135-157.

SÁDABA, T., RODRÍGUEZ, J. y BARTOLOMÉ, M. (2012): Propuesta de sistematización de la teoría del framing para el estudio y praxis de la comunicación política. Observatorio (OBS*), 6 (2), pp. 109-126.

SALAS-PORRAS, A. (2002): Comunicación política, neopopulismo y democracia. Estudios Políticos, no. 30, pp. 91-122.

DOI: http://dx.doi.org/10.22201/fcpys.24484903e.2002.30.37543

VINCENT, L. (2011): La disputa por la mediación durante el kirchnerismo en Argentina. CONfines de relaciones internacionales y ciencia política, 7 (13), pp. 49-81.

VITALE, M. A. y MAIZELS, A. L. (2011): El discurso electoral de Cristina Fernández de Kirchner (2007). Un caso de ethos híbrido no convergente. Linguagem em (Dis)curso, 11 (2), pp. 337-36o. DOI: http://dx.doi.org/10.1590/S1518-76322011000200007

WOLTON, D. (1998): La comunicación política: construcción de un modelo. En FERRY, J. M. y WOLTON, D.: El nuevo espacio público. Barcelona: Gedisa, pp. 28-46.

YANES, R. (2006): Límites éticos del mensaje persuasivo en la comunicación política. ZER. Revista de Estudios de Comunicación, 11 (20), pp. 57-69. 